\title{
Controversy between anesthesiologists and obstetricians on the labour ward: the Delphi method is used as a consensus-building technique
}

\section{Controverse entre anesthésiologistes et obstétriciens en salle de travail: la méthode Delphi est utilisée comme technique de création d'un consensus}

\author{
Nhathien Nguyen-Lu, BMBS · Kristi Downey, MSc • \\ Jose C. A. Carvalho, MD, PhD \\ Received: 26 March 2014/ Accepted: 8 December 2014/Published online: 24 December 2014 \\ (C) Canadian Anesthesiologists' Society 2014
}

\begin{abstract}
Purpose Obstetricians and anesthesiologists may interpret medical evidence differently, which could potentially generate conflict and compromise patient care. We sought to identify the most important controversial topics involving obstetricians and anesthesiologists on the labour ward that had the potential to affect patient outcome.

Methods We conducted a consensus-building study based on the Delphi technique. A panel of experts comprised of obstetric anesthesiologists and obstetricians responded to a series of four parallel sequential questionnaires interspersed with feedback. The first round consisted of an open questionnaire: Which topics in patient management would rouse a difference of opinion between anesthesiologists and obstetricians that may interfere with patient outcome, and why? The second round sought agreement on the topics, and the third round sought to rank
\end{abstract}

Author contributions Nhathien Nguyen-Lu, Kristi Downey, and Jose C.A. Carvalho participated in research design and data collection and interpretation. Nhathien Nguyen-Lu and Jose C.A. Carvalho wrote the manuscript. Kristi Downey reviewed the manuscript.

N. Nguyen-Lu, BMBS · K. Downey, MSc .

J. C. A. Carvalho, MD, PhD ( $\square)$

Department of Anesthesia and Pain Management, Mount Sinai

Hospital, University of Toronto, 600 University Avenue, Room

781, Toronto, ON M5G 1X5, Canada

e-mail: jose.carvalho@uhn.on.ca

J. C. A. Carvalho, MD, $\mathrm{PhD}$

Department of Obstetrics and Gynecology, Mount Sinai

Hospital, University of Toronto, Toronto, ON, Canada the topics, and their underlying reasons, that scored at least $60 \%$ agreement. The final round allowed each discipline insight into the controversies gathered by the other discipline.

Results Ten anesthesiologists and ten obstetricians participated in the study. Anesthesiologists identified twice as many controversial topics as the obstetricians (six vs three, respectively). The obstetricians agreed with all topics identified by the anesthesiologists, but agreed with only five of the $18(28 \%)$ reasons to support them. Anesthesiologists agreed with all topics raised by the obstetricians, but agreed with only three of the six (50\%) reasons to support them.

Conclusions Both the obstetricians and the anesthesiologists identified several controversial topics that may influence clinical practice on the labour ward. This information could serve as the basis to develop educational programs and strategies to improve communication between the two disciplines.

\section{Résumé}

Objectif Les obstétriciens et les anesthésiologistes peuvent interpréter les données médicales probantes de façons différentes, ce qui est susceptible de générer des conflits et compromettre les soins aux patients. Nous avons cherché à identifier les sujets les plus importants ouverts à controverse entre obstétriciens et anesthésiologistes en salle de travail qui pourraient avoir une répercussion surl'évolution des patientes. Méthodes Nous avons mené une étude de création de consensus basée sur la méthode Delphi. Un panel d'experts constitué d'anesthésiologistes obstétricaux et d'obstétriciens a répondu à une série de quatre questionnaires parallèles 
successifs séparés par des retours d'information. Le premier tour consistait en un questionnaire ouvert: Quels thèmes sur la prise en charge des patientes soulèverait une divergence d'opinion entre anesthésiologistes et obstétriciens pouvant interférer avec l'évolution de la patiente, et pourquoi? Le second tour a recherché un accord sur les thèmes et le troisième tour a cherché à classer les thèmes ainsi que leurs fondements qui obtenaient au moins $60 \%$ de convergence. Le dernier tour permettait d'inclure le point de vue de chacune des disciplines dans les controverses réunies par l'autre discipline.

Résultats Dix anesthésiologistes et dix obstétriciens ont participé à l'étude. Les anesthésiologistes ont identifié deux fois plus de sujets controversés que les obstétriciens (respectivement, six contre trois). Les obstétriciens ont été d'accord avec tous les thèmes identifiés par les anesthésiologistes, mais n'ont été d'accord qu'avec seulement cinq des 18 (28\%) raisons qui soutenaient ces thèmes. Les anesthésiologistes ont été d'accord avec tous les thèmes soulevés par les obstétriciens, mais avec seulement trois des six (50\%) raisons les soutenant.

Conclusions Les obstétriciens et les anesthésiologistes ont ensemble identifié plusieurs sujets controversés qui peuvent influencer la pratique clinique en salle de travail. Cette information pourrait servir de base à l'élaboration de programmes éducatifs et de stratégies visant à améliorer la communication entre les deux disciplines.

The practice of maternity care is characterized by close cooperation amongst several healthcare disciplines (anesthesiologists, obstetricians, neonatologists, nurses, and midwives) in the same hospital caring for the same patient.

Anesthesiologists and obstetricians work on the labour ward with the common goal of ensuring a safe and comfortable childbirth experience for women and their families. Despite this shared goal, some best medical practices may be difficult to implement clinically because the two specialties may interpret the medical literature differently. Furthermore, physicians may select and interpret evidence in a way that best fits their own interests. ${ }^{1}$ While some of these practices may not have major implications for patient outcomes, others may. These difficulties are typically perpetuated due to the lack of effective communication between the disciplines. ${ }^{2}$

Major enquiries into maternity services continue to find that ineffective communication is usually associated with poor outcomes for women and babies. ${ }^{3}$ Negative interprofessional interactions involving power struggles between clinicians have been found to be associated with adverse outcomes. ${ }^{4}$ There is an urgent need to investigate the causes and possible cures of ineffective communication and to foster collaboration among the various healthcare professionals working on the labour ward.

Reime et al. conducted a study to identify areas of agreement, disagreement, or ambiguity in knowledge and attitudes that could help reduce misunderstanding and improve cooperation among care providers in obstetrics. They looked at self-reported practices, attitudes, and beliefs of obstetricians, family practitioners, and midwives regarding central issues in childbirth. The study revealed inconsistent viewpoints and ideologies amongst members of each of the three professional groups on issues such as vaginal birth after Cesarean delivery, episiotomy, and use of oxytocin. Significantly different responses on knowledgebased questions showed that family practitioners and midwives were more skeptical about the external validity of the literature on issues such as induction of labour. ${ }^{5}$

An independent inquiry into the safety of maternity services in England in 2008, "Safe Births: Everybody's business", concluded that "safe teams" are the key to improving the safety of maternity care. The inquiry found a number of recurrent difficulties in teamwork performance such as those related to interprofessional relationships, leadership and management, and communication. ${ }^{6}$ Effective teamwork has been shown to reduce patient mortality. In hospitals where more than $60 \%$ of the staff worked in formal teams, mortality was found to be $5 \%$ lower than would have been expected. ${ }^{7}$

It is critical to understand the barriers to implementing best practices in order to explore opportunities for interprofessional education and, hopefully, improve patient care. One step towards understanding the reasons for such barriers is to identify the major controversial medical issues and the reasons behind them.

The primary goal of this study was to determine the core controversial medical issues on the labour ward that rouse differences in opinion between anesthesiologists and obstetricians and to find out why these different views on common topics exist.

\section{Methods}

We received Research Ethics Board approval (REB number 12-0241-E, September 19, 2012) and conducted the study at a single centre, Mount Sinai Hospital in Toronto, over a four-month period from October 2012 to January 2013.

This study was conducted as a prospective double-blind cross-sectional survey based on the Delphi technique for consensus building. 
Our survey included staff anesthesiologists and obstetricians with regular on-call duties on the labour ward at Mount Sinai Hospital. Each participant had more than five years of experience and pledged to participate in all rounds of questionnaires. Anesthesiologists and obstetricians were selected at random once they met the specified criteria. They were approached with an invitation letter sent by e-mail, and their response to the letter and participation in the process was interpreted as informed consent. No written informed consent was sought from the participants.

To obtain a consensus of controversial topics, we used a Delphi technique comprised of four rounds of questionnaires interspersed with feedback via a web-based survey program (www.fluidsurveys.com, Ottawa, ON, Canada). Parallel rounds of questionnaires were sent to both anesthesiologists and obstetricians (Figure). The first three rounds of the Delphi process were kept "within specialty" until the final fourth round where the responses from the members of one discipline were revealed to the members of the other discipline. Two of the three investigators (J.C. and N.N.) were

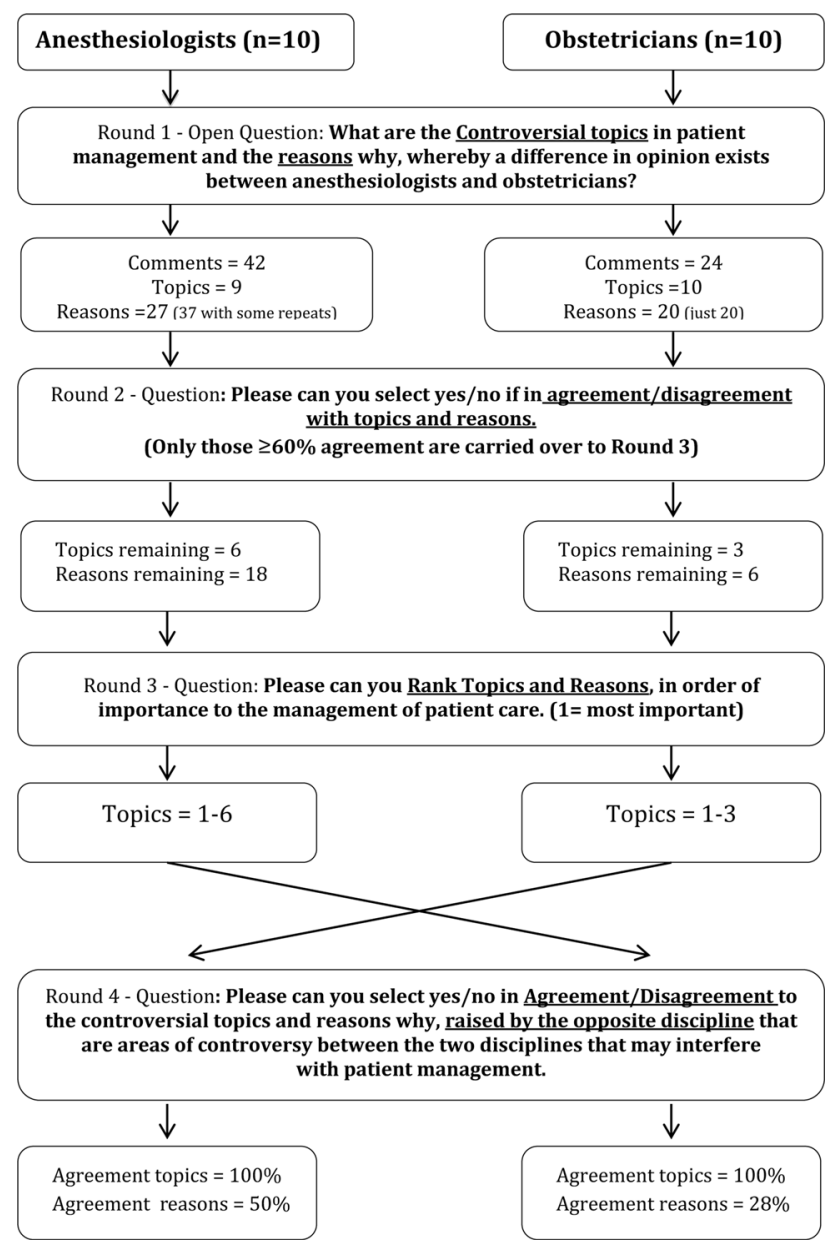

Figure Flowchart illustrating each of the four rounds of the Delphi technique used to achieve agreement of controversial topics and reasons for both anesthesiologists and obstetricians blinded to the identity of the responders, while the unblinded investigator (K.D.) collected and processed the responses throughout the study. Between each round, the blinded investigators organized and grouped the answers they received in order to facilitate the process. This step was completed with unanimous agreement on interpretation and minimal editing of each item, all the while trying to avoid introducing bias into the study.

The first round consisted of two open-ended questions:

1) What are, in YOUR opinion, the topics in patient management on the labour and delivery unit whereby there is a difference of opinion between anesthesiologists and obstetricians important enough to interfere with patient management?

2) For EACH of the topics raised, what do you think are the specific reasons for that difference of opinion? Please give one or more reasons for $\mathrm{EACH}$ topic individually. Feel free to repeat the reasons if they are applicable to more than one topic. Please specify to which topic your reason(s) apply (ies).

After receiving the expert's responses, the three investigators collectively edited the information minimally for brevity and organized the material into a list of topics for the second-round questionnaire.

In the second round, each participant in both groups received a list of all the controversial topics within their own specialty group and the suggested reasons for the differences in opinion. They were asked to review the items that the investigators summarized based on the information provided in the first round and to agree or disagree (state yes/no) with the topics and reasons. This round also provided an opportunity for participants to revise their own judgments and to add new topics should they consider it appropriate.

The third round consisted of a questionnaire and a list of topics and reasons that achieved $\geq 60 \%$ agreement in the second round within each group. The cut off of $\geq 60 \%$ was chosen arbitrarily by the investigators a priori, as we wanted to include as many topics as possible. The participants were asked to rank the topics in order of their perceived importance for patient care. Upon completion of the third round, a list of topics that achieved $\geq 60 \%$ agreement within each group of specialists was produced and ranked by order of importance.

In the final round, the list produced by each of the specialist groups was presented to their counterpart specialty (i.e., anesthesiologist list of issues was presented to the obstetricians and vice versa). The participants were then asked to agree or disagree with the controversial topics and reasons raised by the other discipline. Agreement by $\geq 60 \%$ of the participants in each discipline with the topics and reasons presented by the other discipline was interpreted as the group's agreement with a certain topic or reason. 
Table *Controversial topics identified by obstetricians and anesthesiologists on the labour floor

\begin{tabular}{lll}
\hline Anesthesiologists' Consensus Topics and Underlying & $\begin{array}{l}\text { Obstetricians } \text { Obstetricians' Consensus Topics and } \\
\text { in agreement Underlying Reasons } \\
\text { Reasons }\end{array}$ & $\begin{array}{l}\text { Anesthesiologists } \\
\text { in agreement (\%) }\end{array}$
\end{tabular}

1) Obstetricians' lack of appreciation of anesthetic risks 70

a) Disproportion between surgical risk and anesthetic risk

b) Perioperative management of morbidly obese patients

c) Lack of understanding of the risks of a general vs regional anesthesia

2) Management of high-risk patients

a) Timing of delivery based on different priority goals. i.e., Anesthesiologists focus on 'maternal' risks, Obstetricians on 'fetal' risks.

b) Inadequate consultation and assessment of high-risk patients by obstetricians

c) Postoperative disposition of patients

d) Inadequate referral of selective patients to anesthesia clinic

3) Miscommunication between Anesthesiologists and Obstetricians

a) Lack of joint decisions on $L \& D$

b) Lack of early involvement of anesthesiologists in emergency situations

c) Lack of communication of serious issues and high-risk patients

4) Timing of Cesarean delivery

a) Obstetricians' personal convenience

b) Little consideration given to anesthetic and labour ward workload

c) Lack of concern for patient safety and 'tying up' an OR with elective $C D$.

5) Uterotonic administration

a) Lack of insight and evidence-based medical management in the literature regarding oxytocin dose.

b) Reluctance to change due to culture and tradition

6) Exteriorization of uterus

a) Habit and tradition for obstetrician

b) Claimed better surgical exposure

c) No consideration for the patient discomfort

1) Anesthetic technique for STAT Cesarean 100 deliveries

a) Delayed incision time due to reluctance to $\mathbf{4 0}$ use GA

b) Difference in priorities: maternal safety

(Anesthesiologist) vs fetal safety

(Obstetrician)

20

70

50

c) Lack of understanding that a GA may facilitate surgery

2) Uterotonic administration

a) Difference in 'comfort level' of obstetrics vs anesthesiologists of their use of iv oxytocin and ergot

$\mathrm{GA}=$ general anesthesia; $\mathrm{L} \& \mathrm{D}=$ labour and delivery; $\mathrm{NPO}=$ nil per os; OR = operating room; $\mathrm{CD}=\mathrm{Cesarean}$ delivery

*Controversial topics and reasons that achieved $\geq 60 \%$ agreement are presented in order of importance as ranked by each group of specialists, along with the counterparts' agreement (\%)

The topics are presented in bold and the reasons are presented in italics beneath each topic. The column adjacent to the right of each large column depicts the proportion of experts of the other specialty group that agrees with the topic or reason. The topics and reasons are distinct questions and so the percentages of agreement shown do not sum

Sample size rationale and statistical analysis

The Delphi technique does not call for expert panels to be representative samples for statistical purposes. Representation is assessed on the qualities of the expert panel rather than on its numbers. ${ }^{8}$ What constitutes an optimum number of subjects in a Delphi study never reaches a consensus in the literature. Delbecq et al. have suggested that ten to fifteen subjects could 
be sufficient if the background of the Delphi subjects is homogenous. ${ }^{9}$ Ludwig documents that the majority of Delphi studies have used $15-20$ respondents. ${ }^{10}$ If the sample size is too small, the subjects may not be considered as having provided a representative pooling of judgments regarding the target issue. If the sample size is too large, drawbacks inherent within the Delphi technique can result, e.g., low response rates and an obligation to large blocks of time by respondents and researchers. $^{11}$

We decided to use ten respondents from each of the two groups for an expert panel of 20 respondents for the Delphi process.

We planned to present the results in a descriptive manner. No statistical analysis was performed.

\section{Results}

Ten anesthesiologists and ten obstetricians were approached to participate in the study. One obstetrician and one anesthesiologist could not commit to all rounds of the questionnaire and declined to participate. Arrangements were then made for replacements who agreed to participate. All 20 participants responded to all four rounds of questionnaires. Five male and five female anesthesiologists participated, with a mean (range) age of 45.5 (36-64) yr, and six male and four female obstetricians participated, with a mean (range) age of 52.5 (36-66) yr.

Eight controversial topics were identified. The anesthesiologists identified twice as many topics as the obstetricians (6vs 3, respectively). Uterotonic administration was the only topic raised by both specialties.

The topics and respective reasoning that reached $\geq 60 \%$ agreement in each group of specialists after the four rounds of the Delphi process are presented in the Table. They are ranked in order of importance by each group of specialists. Obstetricians identified the choice of anesthetic technique employed by anesthesiologists during STAT Cesarean delivery as the most controversial topic, and $100 \%$ of anesthesiologists in the panel agreed with that topic. There was, however, a difference of opinion regarding the reasons behind that controversy. The obstetricians' concern that a reluctance to use general anesthesia would lead to a longer time to incision was supported by only $40 \%$ of anesthesiologists. On the other hand, $100 \%$ of anesthesiologists agreed with the obstetricians' observation that they gave greater priority to maternal safety.

Using the cut-off value of $\geq 60 \%$ agreement as representing the groups' agreement with each topic and reason, anesthesiologists agreed with all topics raised by the obstetricians, but agreed with only three of six $(50 \%)$ of the reasons behind the topics. Obstetricians also agreed with all of the topics identified by the anesthesiologists, but agreed with only five of 18 (28\%) of the reasons behind the topics.

\section{Discussion}

The results of this study based on the Delphi technique revealed eight controversial topics between anesthesiologists and obstetricians. Anesthesiologists identified twice as many topics as the obstetricians, with a single overlapping issue. While both disciplines initially identified different topics, once their counterpart's view was presented, both parties were in agreement with all topics. Nevertheless, there was significant disagreement on the underlying reasons for the controversial topics.

The topics and reasons identified by both disciplines reflect a combination of a lack of knowledge base, suboptimal communication, system issues, and practice habits. Furthermore, our results suggest that anesthesiologists have a greater sensitivity to the mother's needs and a greater concern with risk, and they are more dissatisfied with the lack of shared decision-making. A thorough analysis of the topics and reasons may offer opportunities to unveil their root causes and solutions.

There should be an easy solution to some of the topics, such as the adherence to fasting guidelines. Surprisingly, obstetricians perceive anesthesiologists as not having uniform practice around this important subject. Fasting guidelines, however, are clearly established by anesthesiology societies, ${ }^{12,13}$ and their clear communication to all healthcare providers working on the labour ward, anesthesiologists included, should eradicate this controversy.

Other topics, such as mode of uterine repair (in situ vs exteriorized) and use of uterotonics, will require review and discussion of the current medical evidence as well as some commitment from both anesthesiologists and obstetricians to leave old habits behind and embrace best practices. Interestingly, the only topic raised by both groups of specialists was the use of uterotonics to prevent and treat postpartum hemorrhage and the conflicting opinions regarded the most appropriate use of oxytocin at Cesarean deliveries.

Finally, for some of the topics, major effort will be needed to analyze the evidence and promote extensive dialogue and education towards implementation of best practices, including team training. For example, the controversy around the best anesthetic technique in cases of an emergency Cesarean delivery highlights the perception that obstetricians lack appreciation of anesthetic risks and, from the obstetricians' perspective, that anesthesiologists prioritize the safety and wellbeing of the mother over that of the fetus in emergency situations. This common scenario in labour and delivery involves not only knowledge and skills, but also legal and ethical concerns. Most guidelines of different professional organizations have standardized classifications for the urgency of Cesarean delivery and recommend complying with a 30-min decision-to-incision 
interval for emergency Cesarean delivery. ${ }^{14}$ In certain circumstances, an even faster delivery will be required; however, at all times, the mother's safety should not be compromised. Team training in simulated and controlled conditions may offer opportunities for improving communication and performance in preparation for these acute, complex, and stressful situations.

Interestingly, communication amongst healthcare professionals, regarded as a universal and important problem with significant impact on patient outcomes, ${ }^{3}$ was raised solely by anesthesiologists. This may be a result of anesthesiologists' great interest in simulation and non-technical skills applied to crisis management. Nevertheless, although obstetricians did not raise this issue, once miscommunication was presented as a potential controversial topic, they agreed that issues exist regarding communication between the two professions within a labour ward environment.

Our effort at consensus building was based on the Delphi technique. In areas where empirical evidence is lacking, the Delphi technique is a recognized and accepted method used to gather information from experts within a domain of proficiency. The technique is designed as a group exercise that aims to achieve a convergence of opinion that may prove very useful. ${ }^{8-11,15-19}$ The interactions of experts may lead to a reduction in individual bias. The Delphi method is a wellrecognized tool for solving problems in healthcare, and it is increasingly being used to reach consensus around many topics in medicine, including education, development of clinical guidelines, and prioritization of research topics. ${ }^{16,17}$ It has been argued that the forecasting accuracy of the Delphi technique is clearly reliable. For example, a Delphi study involving medical doctors evaluating the forecasting application of the method revealed that, in $75 \%$ of cases, the estimated values proved to be less than $10 \%$ different from the values observed. ${ }^{19}$

Information is lacking in the literature regarding collaboration or teamwork between anesthesiologists and obstetricians. In contrast, many studies have addressed collaboration between nursing staff and physicians., ${ }^{4,5}$ Primary care medicine has long recognized the need for interprofessional practice, with many models of highperformance teams. Several characteristics have been identified in high-performance teams, including effective communication, recognition of member contributions, shared decision-making, and shared vision and values. ${ }^{20}$ The ultimate goal of developing high-functioning teams is to have the ability to provide high-quality care for our patients. The Institute of Medicine has identified teamwork and collaboration as critical competencies to provide safe high-quality care. ${ }^{21}$

There were certain strengths to our study, for example, all respondents maintained their anonymity from the two blinded reviewers as well as from the other Delphi participants. This allowed more opinions to come forward. The perspectives of both anesthesiologists and obstetricians were explored, and a wide variety of senior and experienced doctors were approached.

There are several limitations to our study. It was conducted in a single centre, Mount Sinai Hospital in Toronto, Ontario, Canada, a tertiary obstetric centre with over 7,000 deliveries, of which $50 \%$ are considered high risk. This certainly represents a substantial limitation in the generalizability of the findings. Two of the three investigators are practicing obstetric anesthesiologists, which could have introduced bias into the study despite all best efforts not to impose individual views or mould opinions on the topics raised. There is also the risk that the Delphi participants would rate their responses differently after receiving distorted feedback. ${ }^{9}$ The one-month time restriction placed on each round of the Delphi technique may mean that we did not achieve complete data saturation; however, we stipulated that, for full participation, each subject had to read the applicable responses and reply in each round. Furthermore, we assumed that Delphi subjects were comparable in knowledge and experience. ${ }^{22}$ In reality, however, some participants may have more in-depth knowledge of certain topics than others within their specialty. This may lead to identifying a series of general statements rather than accomplishing an in-depth exploration of each topic. ${ }^{20}$

Given that this preliminary study reflects the opinions collected in a single tertiary care centre, it would be prudent to design a larger follow-up study with a nationwide sample to determine whether the findings from our institution are generalizable and common throughout Canada. Furthermore, it would be valuable to conduct similar studies to identify controversial topics between anesthesiologists and other labour ward health professionals such as nurses and midwives.

The controversial topics and underlying reasons identified in this study may serve as a basis to develop education and training in areas where concordance is lacking between anesthesiologists and obstetricians and could have a significant impact on patient care and outcome.

Funding This study was funded internally by the Department of Anesthesia and Pain Management, Mount Sinai Hospital, University of Toronto.

Declarations of interest We declare no conflict of interests.

Disclosures This paper was presented at the $45^{\text {th }}$ Annual Meeting of the Society of Obstetric Anesthesia and Perinatology, San Juan, Puerto Rico, April 24-28 2013 as a poster. It won best Obstetric Anesthesia Paper 2013 at the Canadian Society of Anesthesiologists' Annual Meeting, Calgary, June 21-24 2013. 


\section{References}

1. Rodwin MA. The politics of evidence-based medicine. J Health Polit Policy Law 2001; 26: 439-46.

2. Leonard M, Graham S, Bonacum D. The human factor: the critical importance of effective teamwork and communication in providing safe care. Qual Saf Health Care 2004; 13(Suppl 1): i85-90.

3. Centre for Maternal and Child Enquiries (CMACE). Saving Mothers' Lives: reviewing maternal deaths to make motherhood safer: 2006-08. The Eighth Report on Confidential Enquiries into Maternal Deaths in the United Kingdom. BJOG 2011; 118(Suppl. 1): 1-203.

4. Hastie C, Fahy K. Inter-professional collaboration in delivery suite: a qualitative study. Women Birth 2011; 24: 72-9.

5. Reime B, Klein MC, Kelly A, et al. Do maternity care provider groups have different attitudes towards birth? BJOG 2004; 111: 1388-93.

6. Walker I, Grise E. Safe Births: Everybody's business: Independent Inquiry Into the Safety of Maternity Services in England. Kings Fund; London; 2008.

7. West MA, Borrill CS. The influence of team working. In: Cox J, King J, Hutchinson A, McAvoy P (Eds). Understanding Doctors' Performance. Oxford: Radcliffe Publishing; 2005.

8. Powell C. The Delphi technique: myths and realities. J Adv Nurs 2003; 41: 376-82.

9. Delbecq AL, Van de Ven AH, Gustafson DH. Group Techniques for Program Planning. Glenview, IL: Scott Foresman Company; 1975.

10. Ludwig B. Predicting the future: have you considered using the Delphi methodology? Journal of Extension 1997; 35: 1-4; Available from URL: http://www.joe.org/joe/1997october/tt2. php/index.php (accessed October 2014).

11. Hsu CC, Sandford BA. The Delphi Technique: Making sense of Consensus. Practical Assessment, Research and Evaluation. 2007; 12:10; Available from URL: http://pareonline.net/getvn. asp? $\mathrm{v}=12 \& \mathrm{n}=10$ (accessed October 2014).

12. American Society of Anesthesiologists Committee. Practice guidelines for preoperative fasting and the use of pharmacologic agents to reduce the risk of pulmonary aspiration: application to healthy patients undergoing elective procedures: an updated report by the American Society of Anesthesiologists Committee on Standards and Practice Parameters. Anesthesiology 2011; 114:495-511.

13. Smith I, Kranke P, Murat I, et al. Perioperative fasting in adults and children: guidelines from the European Society of Anaesthesiology. Eur J Anaesthesiol 2011; 28: 556-69.

14. Royal College of Obstetricians and Gynaecologists. Classification of Urgency of Caesarean Section - a Continuum of Risk (Good Practice No. 11). London: RCOG 2010. Available from URL: http://www.rcog.org.uk/classification-of-urgency-ofcaesarean-section-good-practice-11 (accessed October 2014).

15. Dalkey $N$, Helmer $O$. An experimental application of the Delphi method to the use of experts. Management Science 1963; 9: 458 67.

16. Sinha IP, Smyth RL, Williamson PR. Using the Delphi technique to determine which outcomes to measure in clinical trials: recommendations for the future based on a systematic review of existing studies. PLoS Med 2011; 8: e1000393.

17. Boulkedid R, Abdoul H, Loustau M, Sibony O, Alberti C. Using and reporting the Delphi method for selecting healthcare quality indicators: a systematic review. PLoS One 2011; 6: e20476.

18. Williams $P L, W e b b C$. The Delphi technique: a methodological discussion. J Adv Nurs 1994; 19: 180-6.

19. Linstone HA, Turoff M. The Delphi Method: Techniques and Applications. Reading, MA: Addison-Wesley Publishing Company; 1975: 3-12.

20. Johnson JE. Working together in the best interest of patients. J Am Board Fam Med 2013; 26: 241-3.

21. Greiner A, Knebel E; Committee on the Health Professions Education Summit; Board on Health Care Services. Health Professions Education: A Bridge to Quality. Washington DC: National Academies Press; 2003.

22. Altschuld JW, Thomas PM. Considerations in the application of a modified screen test for Delphi survey data. Eval Rev 1991; 15: $179-88$. 